\title{
Materials from renewable resources based on furan monomers and furan chemistry: work in progress $\dagger$
}

\author{
Alessandro Gandini, * Dora Coelho, Mónica Gomes, Bruno Reis and Armando Silvestre \\ Received 3rd June 2009, Accepted 3rd September 2009 \\ First published as an Advance Article on the web 30th September 2009 \\ DOI: $10.1039 / b 909377 \mathbf{j}$
}

The polymerisation of furan monomers and the exploitation of some of the chemical peculiarities of the furan heterocycle have generated a wide diversity of macromolecular materials based on renewable resources. We present here recent contributions to this field, including ongoing studies on the synthesis and characterisation of novel furan polyesters and on the application of the Diels-Alder reaction to the preparation of linear and branched thermally reversible polyadducts.

\section{Introduction}

Making polymers from renewable resources is an old practice, as old as the birth of macromolecular science and technology toward the end of the nineteenth century. It was then that cellulose esters became important materials and the vulcanization of natural rubber brought tyres into the market. Together with these chemical modifications of natural polymers, "resins" based on terpenes, rosin and, later, furfuryl alcohol and alkyd compositions incorporating vegetable oils acquired growing applications.

The advent of the carbon, natural gas, and petroleum chemical revolutions in the twentieth century provided a myriad of novel macromolecular materials and thus fossil resources became the dominant precursors in this realm, with only modest additional original contributions from their renewable counterparts.

Nearing the end of the last century, the dwindling of fossil resources, together with their unpredictable price fluctuations, raised serious questions about the medium-term pursuit of their exploitation. This refers principally to energy production, but also to their becoming dominant purveyors of organic commodities and materials, with the additional concern of the ecological impact related to their exploitation. The ensuing surge of activities associated with the search for alternative energy sources has been extended to similar initiatives in the context of polymers from renewable resources, as recently reviewed., Monomers, oligomers and polymers produced by nature within the multifarious biological activities associated with the animal and vegetable realms have thus regained a respectable status through the incessantly growing research aimed at turning them into useful materials. These investigations concern chemical transformations (polymerisation, surface or bulk modification, grafting and cross-linking) and/or physical manipulations (making blends, composites, and other multimaterials).

Among this burgeoning ferment of initiatives, polymers prepared from furan monomers and/or some specific features

CICECO and Chemistry Department, University of Aveiro, 3810-193, Portugal. E-mail: agandini@ua.pt; Fax: +351 234 370084; Tel: +351 234370711

$\dagger$ This paper is part of a Journal of Materials Chemistry theme issue on Green Materials. Guest editors: James Clark and Duncan Macquarrie. associated with the chemical peculiarities of that heterocycle constitute a unique class of materials based on vegetable renewable resources, because they encompass a wide variety of structures, simulating virtually all the current fossil-derived counterparts (furan itself was used as a precursor to polytetramethylene glycol, prior to its reduction to tetrahydrofuran). ${ }^{2,3}$ This situation arises from the fact that two first-generation furan compounds, viz. furfural (F) and 5-hydroxymethylfurfural (HMF), readily prepared from polysaccharides or sugars bearing respectively pentose and hexose moieties, can be converted into two large families of monomers. The first refers to moieties susceptible to polymerise or copolymerise via chain-growth processes and includes structures derived from $\mathbf{F}$ by appending various vinyl moieties and acrylic or oxirane groups to the heterocycle, a selection of which is shown in Scheme 1, while the second concerns molecules for step-growth mechanisms, viz. monomers arising from HMF via the introduction, among others, of carboxy, hydroxyl, amino, or isocyanate functions, many of which are portrayed in Scheme 2. HMF is not sufficiently stable to be stored and recent production strategies envisage its in situ oxidation to the corresponding dialdehyde or diacid, both quite stable crystalline compounds.

In addition, difuran monomers for step-growth polymerisations can also be prepared using $\mathbf{F}$ derivatives and appropriate C5-C5 coupling reactions as sketched in Scheme 3.

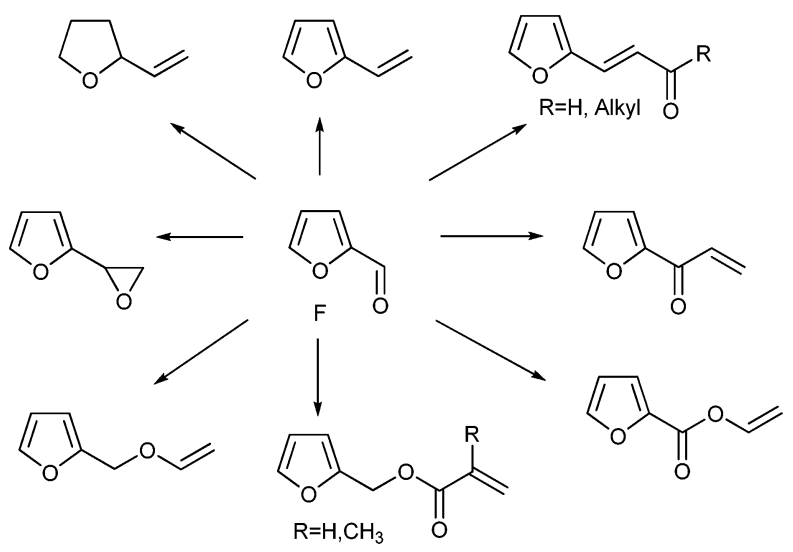

Scheme 1 A selection of monomers derived from furfural (F). 


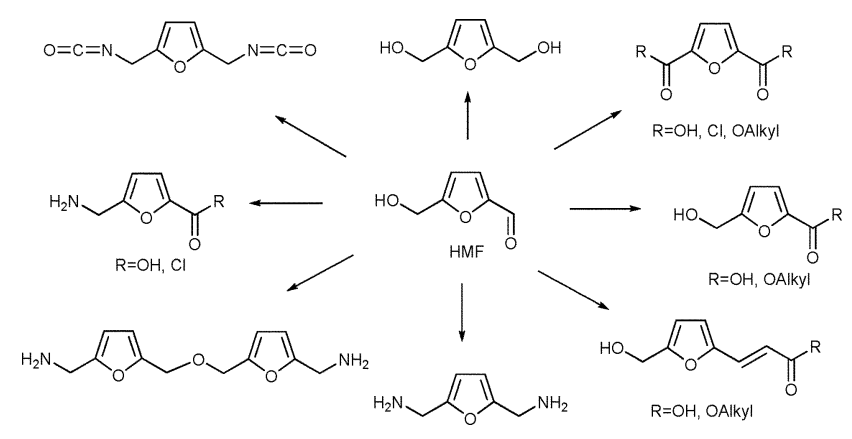

Scheme 2 A selection of monomers derived from 5-hydroxymethylfurfural (HMF).

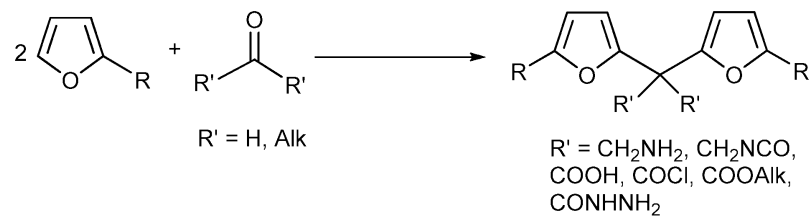

Scheme 3 Difuran monomers derived from 2-substituted furans.

It is important to emphasise that all these monomers have already been synthesised and used in appropriate polymerisation and copolymerisation processes, followed by the characterisation of the ensuing materials. ${ }^{2,3}$ This general strategy has therefore given rise to a novel realm of sustainable macromolecular science, which offers numerous promising alternatives to the corresponding conventional materials obtained from nonrenewable sources. Clearly, the only originality of the structures shown in Schemes 1-3, and hence of the corresponding macromolecules, lies in their incorporation of the furan heterocycle, while otherwise simulating their classical aliphatic and aromatic counterparts. This is however a very important structural difference in terms of the unique possibility of making use of the heterocycle as a promoter of further polymer modifications thanks to its specific reactivity.

The exploitation of these peculiar chemical properties of the furan ring include, among others, (i) electrophilic substitutions to generate reactive end groups, block and graft copolymers, (ii) the coupling of photosensitive chromophores, (iii) the synthesis of conjugated molecules as powerful radical scavengers, and, principally (iv) its proneness to intervene in the Diels-Alder (DA) reaction, a beautiful example of reversible click chemistry, which has opened new ways to synthesise polymers with unique properties, including self-mendability and network recyclability through reversible cross-linking. ${ }^{2-4}$

Given that the outcome of all these studies has been largely documented, including a critical appraisal of the merits and drawbacks of each system in terms of monomer reactivity, side reactions and polymer properties, ${ }^{2-4}$ the present report is restricted to our recent contributions to the field of furan-based polyesters and DA polymers, some of which are still in progress.

\section{Experimental}

This section only describes the synthesis and characterisation of the monomers used in both types of polymerisations, whereas the specificities associated with these different processes will be provided together with the actual results.

\subsection{Monomers for polyesters}

The pure 2,5-furandicarboxylic acid (FDCA) used in this study was a generous gift from Prof. Antoine Gaset of Toulouse National Polytechnic Institute. ${ }^{5}$ Its purity, deemed adequate for its subsequent use as a precursor of the various monomers described below, was confirmed by ${ }^{1} \mathrm{H}$ and ${ }^{13} \mathrm{C}$ NMR spectroscopy and elemental analysis. Its dichloride (monomer I, Scheme 4) was prepared by its reaction with an excess of thionyl chloride under reflux for $4 \mathrm{~h}$, in the presence of DMF and purified by vacuum sublimation to give white crystals $(78 \%$ yield), m.p. $79{ }^{\circ} \mathrm{C} . v$ (FTIR-ATR) $/ \mathrm{cm}^{-1} 3140$ and 3110 (furan $\mathrm{C}=\mathrm{C}), 1737(\mathrm{C}=\mathrm{O})$ and the typical peaks of ring breathing (1007) and of 2,5-substituted furans (824 and 712); $\delta_{\mathrm{H}}(300 \mathrm{MHz}$, $\left.\mathrm{CDCl}_{3}, \mathrm{Me}_{4} \mathrm{Si}\right) 7.54(2 \mathrm{H}$, singlet, furan $\mathrm{H} 3$ and $\mathrm{H} 4) ; \delta_{\mathrm{C}}(75 \mathrm{MHz}$, $\mathrm{CDCl}_{3}, \mathrm{Me}_{4} \mathrm{Si}$ ) 123.2 (furan $\mathrm{C} 3$ and $\mathrm{C} 4$ ), 149.3 (furan $\mathrm{C} 2$ and $\mathrm{C} 5$ ) and $155.9(\mathrm{C}=\mathrm{O})$. The sensitivity of $\mathbf{I}$ to hydrolysis was found to be quite modest, as shown, on the one hand, by its stability in ambient conditions for several days and, on the other, by the fact that when suspended in water at room temperature, its FTIR spectrum only began to show the formation of the corresponding acid after about $30 \mathrm{~min}$.

Bis(hydroxyethyl)-2,5-furandicarboxylate (monomer II, Scheme 4) was obtained in $98 \%$ yield by the $\mathrm{HCl}$-catalysed esterification of FDCA with a large excess of ethylene glycol, followed by its purification by high-vacuum distillation of the excess glycol: $v$ (FTIR-ATR)/ $/ \mathrm{cm}^{-1} 3340(\mathrm{OH}), 1716(\mathrm{C}=\mathrm{O})$, 1020 (ring breathing) and $887+771$ (2,5-dibustituted furan); $\delta_{\mathrm{H}}$ $\left(300 \mathrm{MHz}, \mathrm{C}_{3} \mathrm{D}_{6} \mathrm{O}, \mathrm{Me}_{4} \mathrm{Si}\right) 3.86\left(4 \mathrm{H}\right.$, triplet, $\left.\mathrm{CH}_{2} \mathrm{OH}\right), 4.38(4 \mathrm{H}$, triplet, $\left.\mathrm{COOCH}_{2}\right), 7.37(2 \mathrm{H}$, singlet, furan $\mathrm{H} 3$ and $\mathrm{H} 4)$ and a broad $\mathrm{OH}$ peak between 3.5 and $4.2 ; \delta_{\mathrm{C}}\left(75 \mathrm{MHz}, \mathrm{C}_{3} \mathrm{D}_{6} \mathrm{O}\right.$, $\left.\mathrm{Me}_{4} \mathrm{Si}\right) 60.6\left(\mathrm{CH}_{2} \mathrm{OH}\right), 67.6\left(\mathrm{COOCH}_{2}\right), 119.7$ (furan $\mathrm{C} 3$ and C4), 147.7 (furan $\mathrm{C} 2$ and $\mathrm{C} 5$ ) and $158.7(\mathrm{C}=\mathrm{O})$. A similar procedure was adopted to prepare and purify bis(hydroxypropyl)-2,5-furandicarboxylate (monomer III, Scheme 4) using 1,3-propylene glycol. Its FTIR spectrum was, as expected, very similar to that of II. In its ${ }^{1} \mathrm{H}$ and ${ }^{13} \mathrm{C}$ NMR spectra, the only relevant difference with respect to those of II was the extra peak at $2.0 \mathrm{ppm}$ for the intermediate $\mathrm{CH}_{2}$ protons and at $33.9 \mathrm{ppm}$ for

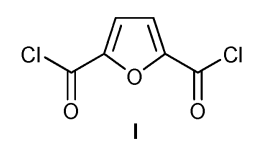<smiles>O=C(OCCCO)c1ccc(C(=O)OCCCO)o1</smiles><smiles>OC1COC2COCC12</smiles><smiles>O=C(OCCO)c1ccc(C(=O)OCCO)o1</smiles>

II

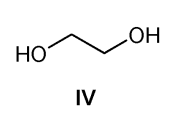


its carbon atom. $v$ (FTIR-ATR)/ $/ \mathrm{cm}^{-1} 3279(\mathrm{OH}), 3152+3120$ (furan $\mathrm{C}=\mathrm{C}), 2966+2928+2872\left(\mathrm{CH}_{2}\right), 1725(\mathrm{C}=\mathrm{O}), 1023$ (ring breathing) and $885+770$ (2,5-dibustituted furan); $\delta_{\mathrm{H}}$ (300 MHz, $\mathrm{CDCl}_{3}, \mathrm{Me}_{4} \mathrm{Si}$ ) 2.00 (4H, quintet, $\mathrm{CH}_{2} \mathrm{CH}_{2} \mathrm{CH}_{2} \mathrm{OH}$ ), $3.78\left(4 \mathrm{H}\right.$, triplet, $\left.\mathrm{CH}_{2} \mathrm{CH}_{2} \mathrm{CH}_{2} \mathrm{OH}\right), 4.50(4 \mathrm{H}$, triplet, $\left.\mathrm{COOCH}_{2}\right), 7.22(2 \mathrm{H}$, singlet, furan $\mathrm{H} 3$ and $\mathrm{H} 4)$ and a $\mathrm{OH}$ peak at 2.19; $\delta_{\mathrm{C}}\left(75 \mathrm{MHz}, \mathrm{CDCl}_{3}, \mathrm{Me}_{4} \mathrm{Si}\right) 33.9\left(\mathrm{CH}_{2} \mathrm{CH}_{2} \mathrm{CH}_{2} \mathrm{OH}\right), 58.9$ $\left(\mathrm{CH}_{2} \mathrm{CH}_{2} \mathrm{CH}_{2} \mathrm{OH}\right), 62.6\left(\mathrm{COOCH}_{2}\right), 118.6$ (furan $\mathrm{C} 3$ and $\mathrm{C} 4$ ), 146.6 (furan $\mathrm{C} 2$ and $\mathrm{C} 5$ ) and $158.2(\mathrm{C}=\mathrm{O})$. Ethylene glycol (monomer IV, Scheme 4) of the highest purity commercially available was used as received. The same applies to the other two diols employed here, viz. dianhydro-D-glucitol or D-isosorbide (monomer V, Scheme 4) and bis(1,4-hydroxymethyl)benzene (monomer VI, Scheme 4). The absence of detectable impurities in these commercial products was however confirmed by FTIR and both ${ }^{1} \mathrm{H}$ and ${ }^{13} \mathrm{C}$ NMR spectroscopy.

\subsection{Monomers for DA polymerisations}

Both linear and branched polymers are discussed in this investigation, hence the preparation of monomers with two or more functionalities. The DA combination studied here is the most thoroughly examined couple in this type of polymer synthesis, viz. that involving the furan heterocycle as the dienic partner and the maleimide moiety as the complementary dienophiles. ${ }^{3,4}$ The structures of the bisfuran monomers were chosen with the purpose of preparing flexible polymer chains, i.e., materials with relatively low Tg. Monomer VII (Scheme 5) was synthesised, purified and characterised following a previously reported procedure involving the esterification of adipoyl chloride with furfuryl alcohol in the presence of triethylamine. ${ }^{6}$

The preparation of monomer VIII (Scheme 5) called upon two steps, viz. the formation of the double Schiff base from furfural (20\% molar excess) and 4,7,10-trioxa-1,13-tridecanediamine in absolute methanol for $5 \mathrm{~h}$ at room temperature, followed by the reduction of the $\mathrm{C}=\mathrm{N}$ bonds with an excess of $\mathrm{NaBH}_{4}$ for $2 \mathrm{~h}$ at room temperature. This solution was concentrated under vacuum, diluted with $\mathrm{CHCl}_{3}$ and washed several times with water. The organic phase was dried and the solvents removed under vacuum leaving a viscous oil ( $80 \%$ overall yield): $v$ (FTIRATR) $/ \mathrm{cm}^{-1} 3305(\mathrm{NH}), 3109$ (furan $\left.\mathrm{C}=\mathrm{C}\right), 2912\left(\mathrm{asCH}_{2}\right), 2862$ $\left(\mathrm{sCH}_{2}\right), 1346(\mathrm{C}-\mathrm{N}), 1103(\mathrm{C}-\mathrm{O}-\mathrm{C}), 1010$ (ring breathing), $914+$ 740 (furan $\mathrm{CH}) ; \delta_{\mathrm{H}}\left(300 \mathrm{MHz} ; \mathrm{CDCl}_{3}, \mathrm{Me}_{4} \mathrm{Si}\right) 1.63(1 \mathrm{H}$, br s, $\mathrm{NH}), \quad 1.78\left(2 \mathrm{H}\right.$, quintet, $\left.\mathrm{CH}_{2} \mathrm{CH}_{2} \mathrm{CH}_{2}\right), 2.70 \quad(2 \mathrm{H}, \mathrm{t}$, $\left.\mathrm{CH}_{2} \mathrm{NHCH}_{2}\right), 3.50-3.64\left(6 \mathrm{H}, \mathrm{m}, 3 \times \mathrm{OCH}_{2}\right), 3.76(2 \mathrm{H}$, s, furan$\left.\mathrm{CH}_{2} \mathrm{NH}\right), 6.16\left(1 \mathrm{H}, \mathrm{d}\right.$, furan $\left.H_{3}\right), 6.30\left(1 \mathrm{H}\right.$, dd, furan $\left.H_{4}\right), 7.35$ $\left(1 \mathrm{H}, \quad \mathrm{d}\right.$, furan $\left.H_{5}\right) ; \quad \delta_{\mathrm{C}}\left(75 \mathrm{MHz} ; \mathrm{CDCl}_{3}, \mathrm{Me}_{4} \mathrm{Si}\right) 29.8$ $\left(\mathrm{CH}_{2} \mathrm{CH}_{2} \mathrm{CH}_{2}\right), 46.2\left(\mathrm{CH}_{2} \mathrm{NHCH}_{2}\right), 46.4$ (furan- $\left.\mathrm{CH}_{2} \mathrm{NH}\right), 69.7$, 70.1 and $70.5\left(3 \times \mathrm{OCH}_{2}\right), 106.7$ (furan $\mathrm{C3}$ ), 110.0 (furan $\mathrm{C4}$ ), 141.6 (furan $C 5$ ), 154.0 (furan $C 2$ ). An identical protocol was applied to the synthesis of trisfuran monomers IX and $\mathbf{X}$ (Scheme 5) from tris(2-aminoethyl)amine and Jeffamine T-403 (a commercial oligopropylene oxide primary triamine), respectively, both prepared in 90\% overall yield. IX: $v$ (FTIR-ATR)/ $\mathrm{cm}^{-1} 3105(\mathrm{NH}), 3113$ (furan $\left.\mathrm{C}=\mathrm{C}\right), 2887\left(\mathrm{asCH}_{2}\right), 2819\left(\mathrm{sCH}_{2}\right)$, $1146(\mathrm{C}-\mathrm{N}), 1008$ (ring breathing), $916+728$ (furan $\mathrm{CH}$ ); $\delta_{\mathrm{H}}(300$ $\left.\mathrm{MHz} ; \mathrm{CDCl}_{3}, \mathrm{Me}_{4} \mathrm{Si}\right) 2.10(1 \mathrm{H}$, br s, $\mathrm{NH}), 2.53(2 \mathrm{H}, \mathrm{t}$, $\left.\mathrm{NCH}_{2} \mathrm{CH}_{2}\right), 2.63\left(2 \mathrm{H}, \mathrm{t}, \mathrm{NCH}_{2} \mathrm{CH}_{2}\right), 3.74(2 \mathrm{H}$, s, furan$\left.\mathrm{CH}_{2} \mathrm{NH}\right), 6.14\left(1 \mathrm{H}, \mathrm{d}\right.$, furan $\left.H_{3}\right), 6.29\left(1 \mathrm{H}, \mathrm{dd}\right.$, furan $\left.H_{4}\right), 7.32$<smiles>O=C(CCCCC(=O)OCc1ccco1)OCc1ccco1</smiles><smiles>c1coc(CNCCCOCCOCCOCCCNCc2ccco2)c1</smiles><smiles>[X]c1ccc(CNCCN(CCNCc2ccco2)CCNCc2ccco2)o1</smiles>

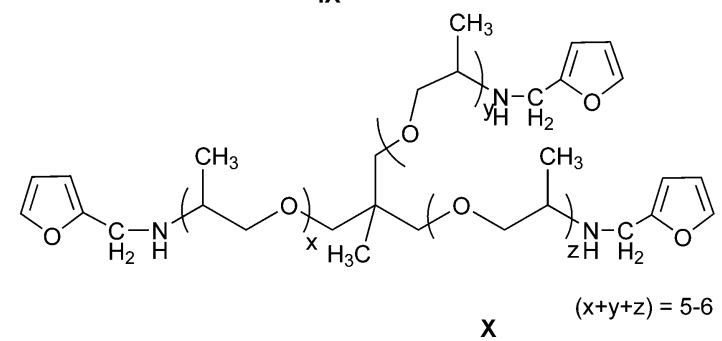<smiles>O=C1C=CC(=O)N1CCCCCCN1C(=O)C=CC1=O</smiles><smiles>[X][X]C1=CC(=O)N(CCCOCCOCCOCCCN2C(=O)C=CC2=O)C1=O</smiles><smiles>[M]C1=CC(=O)N(CCN(CCN2C(=O)C=CC2=O)CCN2C(=O)C=CC2=O)C1=O</smiles>

Scheme 5 Monomers used for the DA and retro-DA reactions.

$\left(1 \mathrm{H}, \mathrm{d}\right.$, furan $\left.H_{5}\right) ; \delta_{\mathrm{C}}\left(75 \mathrm{MHz} ; \mathrm{CDCl}_{3}, \mathrm{Me}_{4} \mathrm{Si}\right) 46.0\left(\mathrm{NCH}_{2} \mathrm{CH}_{2}\right)$, 46.6 (furan- $\mathrm{CH}_{2} \mathrm{NH}$ ), $54.2\left(\mathrm{NCH}_{2} \mathrm{CH}_{2}\right), 106.7$ (furan $\mathrm{C3}$ ), 110.0 (furan C4), 141.6 (furan C5), 153.8 (furan C2). X: $v$ (FTIR$\mathrm{ATR}) / \mathrm{cm}^{-1} 3113$ (furan $\left.\mathrm{C}=\mathrm{C}\right), 2966\left(\mathrm{asCH}_{3}\right), 2939\left(\mathrm{asCH}_{2}\right)$, $2867\left(\mathrm{sCH}_{2}\right), 1146(\mathrm{C}-\mathrm{N}), 1100(\mathrm{C}-\mathrm{O}-\mathrm{C}), 1010$ (ring breathing), $917+730$ (furan $\mathrm{CH}$ ); $\delta_{\mathrm{H}}\left(300 \mathrm{MHz} ; \mathrm{CDCl}_{3}, \mathrm{Me}_{4} \mathrm{Si}\right) 0.80-3.54$ (core jeffamine protons), $3.82\left(2 \mathrm{H}, \mathrm{s}\right.$, furan- $\left.\mathrm{CH}_{2} \mathrm{NH}\right), 6.16(1 \mathrm{H}$, d, furan $\left.H_{3}\right), 6.28(1 \mathrm{H}$, dd, furan $H), 7.34\left(1 \mathrm{H}\right.$, d, furan $\left.H_{5}\right) ; \delta_{\mathrm{C}}$ (75 MHz; $\mathrm{CDCl}_{3}, \mathrm{Me}_{4} \mathrm{Si}$ ) 10-80 (core jeffamine carbons), 44.1 (furan- $\mathrm{CH}_{2} \mathrm{NH}$ ), 106.9 (furan $\mathrm{C} 3$ ), 110.4 (furan $\mathrm{C4}$ ), 141.9 (furan C5), 154.6 (furan $C 2$ ). 
The bismaleimide monomers XI and XII (Scheme 5) were prepared from the corresponding 1,6-diaminohexane and 4,7,10trioxa-1,13-tridecanediamine in the classical two-step process involving the dehydration of the maleamic acid intermediates, as already reported. ${ }^{6}$ The synthesis of the trifunctional maleimide monomer XIII (Scheme 5) employed the reaction of tris(2-aminoethyl)amine with the furan-maleic anhydride DA adduct (exo-3,6-epoxy-1,2,3,6-tetrahydrophthalic anhydride), in stoichiometric conditions, carried out in absolute methanol at $56{ }^{\circ} \mathrm{C}$ for three days, which gave the corresponding trifunctional DA adduct as a yellowish solid precipitate. This intermediate was dissolved in toluene and submitted to the deprotective retro-DA reaction, by progressively liberating furan over $24 \mathrm{~h}$ of reflux. The ensuing yellowish solid, m.p. $170{ }^{\circ} \mathrm{C}$, isolated by vacuumevaporating the toluene, washing with hexane and drying $(60 \%$ overall yield), gave a satisfactory structural characterisation, viz. $v($ FTIR-ATR $) / \mathrm{cm}^{-1} 3098(=\mathrm{CH}), 2950\left(\mathrm{asCH}_{2}\right), 2858\left(\mathrm{sCH}_{2}\right)$, 1762 and $1687(2 \times \mathrm{C}=\mathrm{O}), 1121(\mathrm{C}-\mathrm{N}) ; \delta_{\mathrm{H}}\left(300 \mathrm{MHz} ; \mathrm{CDCl}_{3}\right.$, $\left.\mathrm{Me}_{4} \mathrm{Si}\right) \quad 2.71 \quad\left(2 \mathrm{H}, \quad \mathrm{t}, \quad(\mathrm{CO})_{2} \mathrm{NCH}_{2} \mathrm{CH}_{2}\right), \quad 3.52 \quad(2 \mathrm{H}, \quad \mathrm{t}$, $\left.(\mathrm{CO})_{2} \mathrm{NCH}_{2} \mathrm{CH}_{2}\right), 6.67(2 \mathrm{H}, \mathrm{s}$, maleimide $\mathrm{CH}=\mathrm{CH}) ; \delta_{\mathrm{C}}(75$ $\left.\mathrm{MHz} ; \quad \mathrm{CDCl}_{3}, \quad \mathrm{Me}_{4} \mathrm{Si}\right) \quad 35.6 \quad\left((\mathrm{CO})_{2} \mathrm{NCH}_{2} \mathrm{CH}_{2}\right), \quad 51.6$ $\left((\mathrm{CO})_{2} \mathrm{NCH}_{2} \mathrm{CH}_{2}\right), 134.0$ (maleimide $\left.\mathrm{CH}=\mathrm{CH}\right), 170.6(\mathrm{C}=\mathrm{O})$.

\section{Results and discussion}

\subsection{Polyesters}

Furan polyesters have their own rather long history, first with scattered investigations, ${ }^{7}$ often lacking in essential information, then with the thorough study conducted by Moore and Kelly in the late nineteen-seventies ${ }^{8}$ and, more recently, with a series of studies dealing with the use of the difuran acid, chloride and esters shown in Scheme 3. ${ }^{3}$ Several reasons prompted us to tackle anew this family of polymers, and more specifically those derived from FDCA, namely (i) the recent upsurge of major contributions to the preparation of HMF using highly efficient processes, ${ }^{9}$ which places this compound in a novel industrial perspective by turning it into a viable commodity, consequently opening the way for the production of sizable quantities of FDCA at a reasonable price; (ii) the fact that among the numerous structures previously reported, that of the furan counterpart of the most important commercial polyester, poly(ethylene terephthalate) (PET), had not received any serious attention; (iii) the utilization of diol comonomers with specific features, including their renewable origin and/or their aptitude to give biodegradable polyesters.

The initial polycondensation processes selected for these syntheses called upon well-known mechanisms and procedures, albeit adapted to the novel context. In the specific instance of poly(ethylene 2,5-furandicarboxylate) (PEF), viz. the furan version of PET, the conventional system involving the dichloride I and ethylene glycol (monomer IV) reacting in 1,1,2,2-tetrachloroethane (TCE) at room temperature in the presence of pyridine (Scheme 6) gave the expected polyester (FTIR, NMR, see below), but with a rather low DPn of about 70 .

In order to increase its molecular weight and apply a green process, we switched to a transesterification approach applied to monomer II (Scheme 4). After a series of runs aimed at finding the optimum polymerisation conditions, a satisfactory procedure

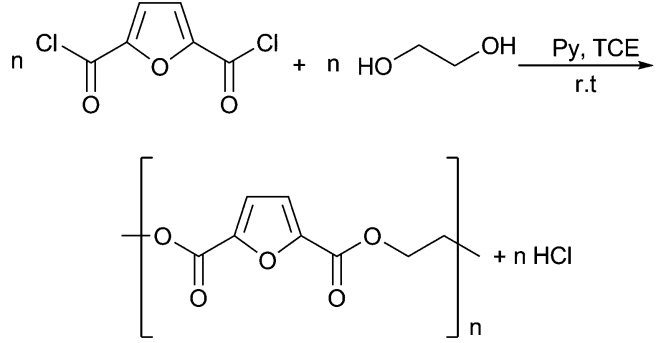

Scheme 6 PEF synthesis via the polycondensation of I with IV.
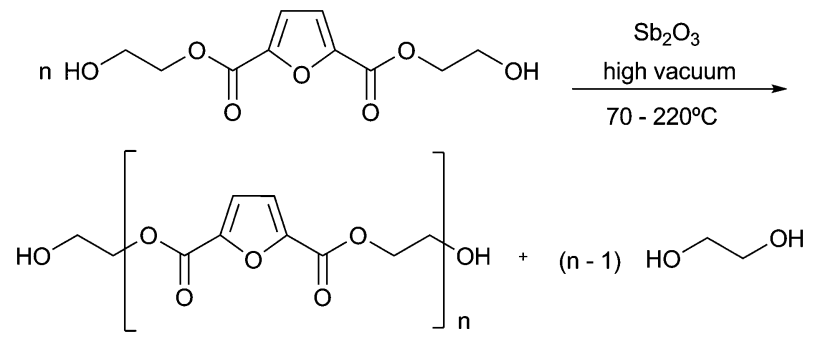

Scheme 7 PEF synthesis via the polytransesterification of monomer II.

was attained and adopted, as described here (Scheme 7). II was mixed with $1 \%$ of $\mathrm{Sb}_{2} \mathrm{O}_{3}$ in a round-bottom flask provided with a magnetic stirrer. The flask was connected to a high vacuum line through a liquid nitrogen trap and the temperature raised rapidly to $70{ }^{\circ} \mathrm{C}$ and then progressively to $220^{\circ} \mathrm{C}$ under stirring in steps of $\sim 10{ }^{\circ} \mathrm{C}$, every time the condensation of the released ethylene glycol in the trap visibly stopped. This was accompanied by a continuous increase in viscosity, until the product turned into a solid mass, at which point the polymerisation was stopped by bringing the system back to room temperature. A brief account of this synthesis was previously published. ${ }^{10}$

In contrast to the PEF prepared from I + IV as described above, this material was insoluble in TCE and only dissolved in trifluoacetic acid (TFA) and in 1,1,1,3,3,3-hexafluoro-2-propanol (HFP), suggesting a higher DP and/or crystallinity. Its thorough characterisation first involved the verification of the expected polymer structure. The typical FTIR spectrum shown in Fig. 1 was essentially the same as that of its precursor II, except, as expected, for the absence of detectable $\mathrm{OH}$ bands at 3340 and $1080 \mathrm{~cm}^{-1}$. The ${ }^{1} \mathrm{H}$ NMR spectrum of PEF in $\mathrm{C}_{2} \mathrm{~F}_{6} \mathrm{CDOD}$ was entirely similar to that taken previously in TFA, ${ }^{10}$ with two singlets with an integration ratio of 2 , at 4.80 and $7.31 \mathrm{ppm}$, attributed respectively to the methylene and furan $\mathrm{H} 3+\mathrm{H} 4$ protons. The ${ }^{13} \mathrm{C}$ NMR spectrum given in Fig. 2 is equally straightforward with signals at $64.5 \mathrm{ppm}$ for the methylene carbons, 121.1 for the ring C3 and C4, 146.8 for the ring C2 and C5 and 160.9 for the carbonyl carbon.

In order to assess the DP of this polyester, two samples from different syntheses were each dissolved in TFA and treated with an excess of pentafluorobenzoyl chloride to esterify both terminal $\mathrm{OH}$ groups. After reprecipitation in methanol and thorough rinsing with it, the modified polymers were submitted to elemental analysis, which gave C $52.2 \pm 0.3, \mathrm{H} 3.4 \pm 0.1, \mathrm{O}$ $44.3 \pm 0.3, \mathrm{~F} 0.38 \pm 0.04$, corresponding to a DPn of $\sim 250$, assuming complete end-group modification. This high molecular 


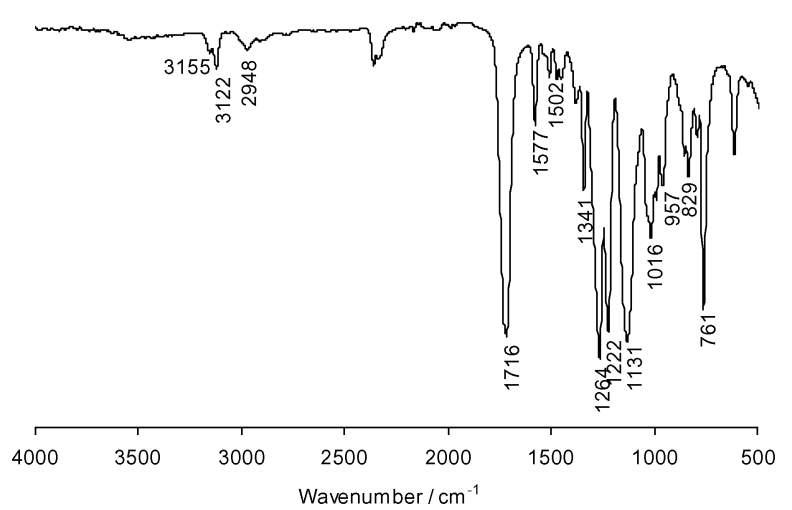

Fig. 1 FTIR spectrum of a sample of PEF prepared according to Scheme 7.

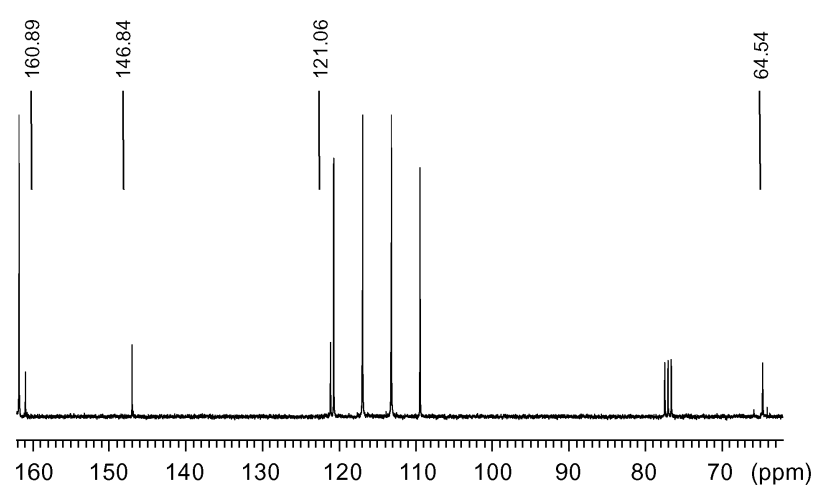

Fig. $2{ }^{13} \mathrm{C}$ NMR spectrum of a sample of PEF prepared according to Scheme 7 (solvent TFA with a drop of $\mathrm{CDCl}_{3}$ ).

weight suggests that the transesterification conditions were quite adequate for monomer II.

These pristine PEFs displayed a high degree of crystallinity, as indicated by their X-ray diffraction pattern ${ }^{10}$ and DSC thermograms (Fig. 3), the latter giving a melting temperature around $210^{\circ} \mathrm{C}$ and a Tg, after quenching, close to $80^{\circ} \mathrm{C}$. A second scan, run after cooling PEFs slowly from the melt, only showed a melting endotherm at $212{ }^{\circ} \mathrm{C}$, corroborating their high aptitude to crystallise. They were found to be thermally stable (Fig. 4) up to $300{ }^{\circ} \mathrm{C}$, with a steep degradation feature around $400{ }^{\circ} \mathrm{C}$.

Monomer III (Scheme 4) was submitted to the transesterification process described above for monomer II (Scheme 7)

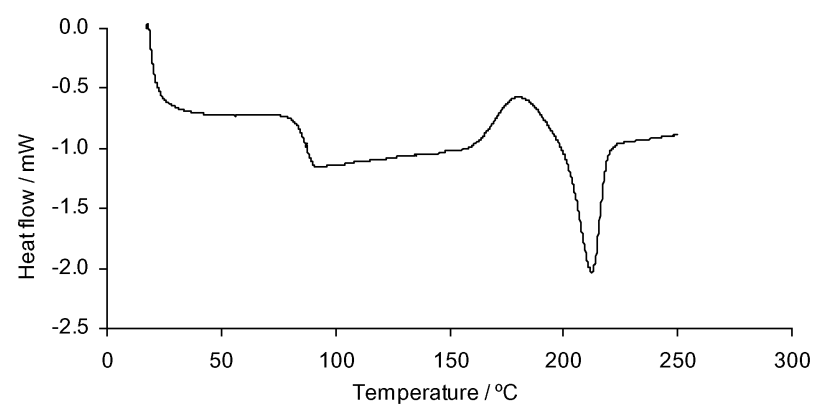

Fig. 3 DSC of PEF after melting the sample at $230{ }^{\circ} \mathrm{C}$ and quenching it in liquid nitrogen.

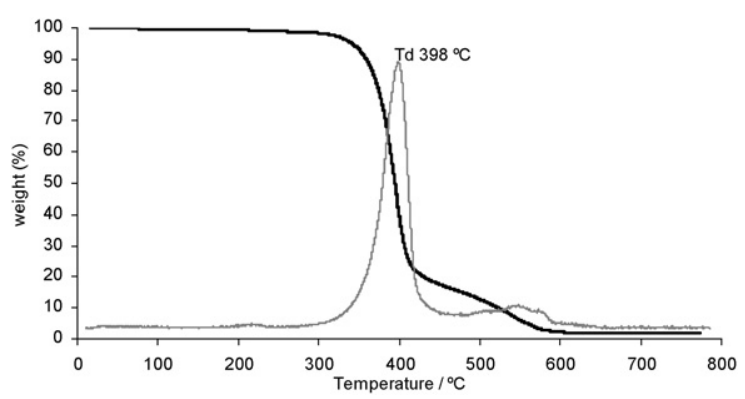

Fig. 4 Typical TGA of PEF in a nitrogen flow.

in order to prepare poly(propylene 2,5-furandicarboxylate) (PPF).<smiles>CC(C)COC(=O)c1ccc(C(=O)OCCCO)o1</smiles>

PPF

The only difference in behaviour was that, with this system, the vacuum removal of the less volatile condensation product was slower, but with $10^{-5} \mathrm{mmHg}$, all the released 1,3-propylene glycol was indeed trapped. As in the case of the minor spectroscopic differences between II and III discussed above, the FTIR and NMR spectra of PPF were very similar to those of PEF, except for the characteristic resonances associated with the extra middle $\mathrm{CH}_{2}$ group. PPF had a melting temperature of $174{ }^{\circ} \mathrm{C}$ and a $\mathrm{Tg}$ of $65^{\circ} \mathrm{C}$, both lower than those of its PEF homologue, as expected, because of the higher macromolecular flexibility brought about by the additional methylene moiety in each polymer unit. Its thermal degradation in a nitrogen atmosphere started at $\sim 300{ }^{\circ} \mathrm{C}$ with a drastic mass loss peaking at $\sim 393{ }^{\circ} \mathrm{C}$. The X-ray diffraction pattern of PPF gave peaks at $2 \theta=11.0$, $16.4,22.5$, and $27.8^{\circ}$. Its end-group derivatisation with pentafluorobenzoyl chloride in TFA and subsequent elemental analysis gave fluorine contents which again pointed to a DPn of about 250 , thus confirming that the system chosen for the polymerisation of II applied equally well to III.

The use of non-volatile diols precludes the application of the process of transesterification adopted above for PEF and PPF. We reverted therefore to the conventional polycondensation process described above and illustrated in Scheme 6 to synthesize two additional furan polyesters based on $\mathbf{I}$ and diols $\mathbf{V}$ and $\mathbf{V I}$, respectively.

The product of $\mathbf{I}+\mathbf{V}$, i.e. with both monomers from renewable resources, was isolated by precipitation in methanol ( $85 \%$ yield). The results of its characterisation were compared with those reported in a similar brief study. ${ }^{11}$ Its FTIR, spectrum shown in Fig. 5 and not reported previously, suggested a relatively high DP because of the absence of any $\mathrm{OH}$ absorption around $3400 \mathrm{~cm}^{-1}$. Both the ${ }^{1} \mathrm{H}$ and ${ }^{13} \mathrm{C}$ NMR spectra were in tune with previous data and confirmed the anticipated polyester structure XIV.

Its $\mathrm{Tg}$ was close to $180^{\circ} \mathrm{C}$ (highly stiff monomer sequence) and its thermal degradation under nitrogen started at $\sim 350{ }^{\circ} \mathrm{C}$ with complete mass loss at $450{ }^{\circ} \mathrm{C}$. 


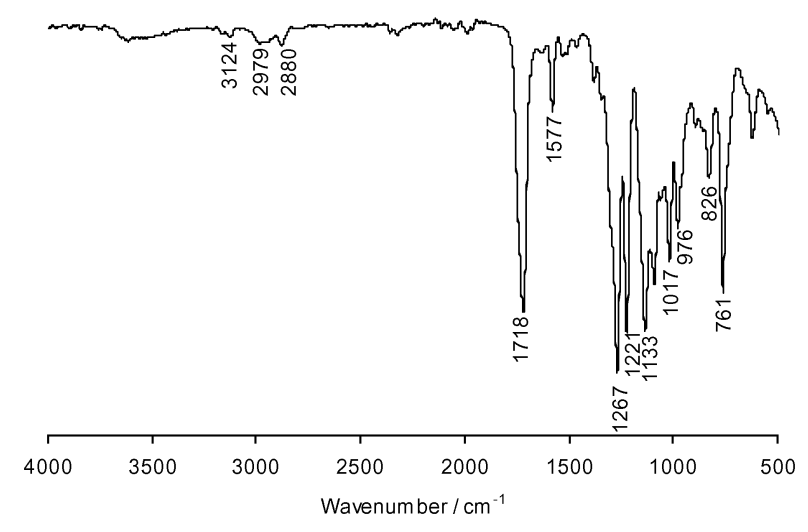

Fig. 5 FTIR spectrum of polyester XIV.

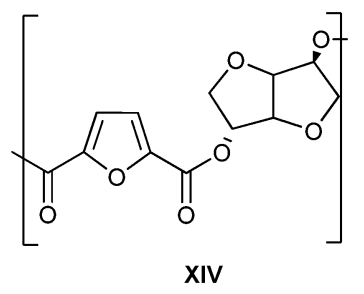

The polyester prepared with I + VI in $75 \%$ yield after precipitation in methanol, gave clean-cut spectra which corroborated the expected structure XV. Fig. 6 shows its FTIR spectrum which again lacked any absorption in the $\mathrm{OH}$ stretching region. The ${ }^{1} \mathrm{H}$ NMR resonances of its solution in $\mathrm{C}_{3} \mathrm{~F}_{6}$ DOD appeared at 5.38 ppm for the methylene protons, 7.30 for the furan $\mathrm{H} 3$ and $\mathrm{H} 4$, and 7.43 for the aromatic counterparts, with the correct integration ratio of $2: 1: 2$. The ${ }^{13} \mathrm{C} \mathrm{NMR}$ spectrum in the same solvent gave peaks $\left(\delta\right.$, ppm) at $66.4\left(\mathrm{CH}_{2}\right), 120.4$ (furan $\mathrm{C} 3$ and C4), 128.9 (unsubstituted aromatic carbons), 135.7 (parasubstituted aromatic carbons), 147.1 (furan C2 and C5) and $160.7(C=\mathrm{O})$. The $\mathrm{Tg}$ of this novel polyester was close to $90^{\circ} \mathrm{C}$

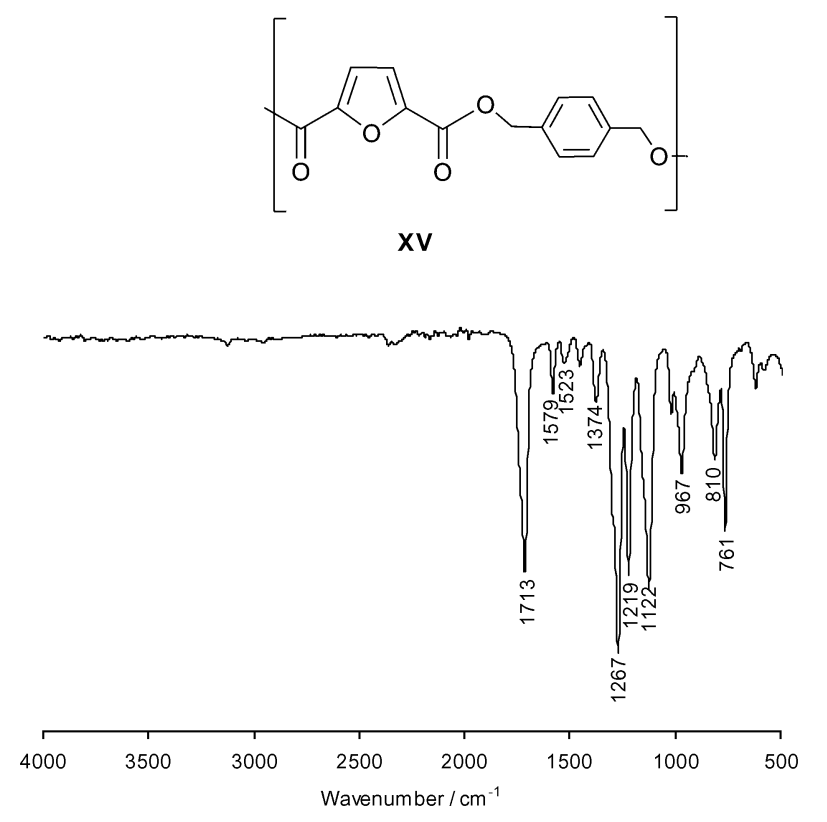

Fig. 6 FTIR spectrum of polymer XV. and its degradation under nitrogen began at $\sim 300{ }^{\circ} \mathrm{C}$. The melting temperature of its crystalline domains was $185{ }^{\circ} \mathrm{C}$. Hence, the presence of both furan and aromatic rings, separated by carboxymethylene moieties, gave rise to thermal transitions in the same temperature range as with PET and PEF, and a reasonable aptitude to crystallisation.

\subsection{Diels-Alder polymers}

Scheme 8 illustrates the essence of the mechanism involved in the present DA and retro-DA reactions, which occur at every step of the polymer growth or of its unzipping, whether linear or branching. The emphasis here is on the role of the temperatures chosen to shift drastically the equilibrium from predominant adduct formation (polymerisation), viz. $65{ }^{\circ} \mathrm{C}$, to the predominant reversion to its precursors (depolymerisation), viz. $110{ }^{\circ} \mathrm{C}$. Systems of this kind are excellent examples of reversible click chemistry applied to macromolecular synthesis. The stereochemical aspects related to the relative abundance of the exo and endo forms of the adducts are not relevant in this specific context, since both play the same role as chain links between monomer units.

The formation of linear macromolecules from the step-growth mechanism associated with the successive DA reactions involving the bisfuran monomers VII and VIII and their complementary bismaleimides XI and XII was achieved by letting equimolar solutions of each pair (at concentrations varying from 0.1 to $2 \mathrm{M}$ ) in TCE or its deuterated counterpart evolve at $65^{\circ} \mathrm{C}$ while stirring under nitrogen. The progress of the reactions was followed by UV and ${ }^{1} \mathrm{H}$ NMR spectroscopy and more qualitatively by the increase in the viscosity of the medium, particularly when high initial monomer concentrations were selected. The first technique provided quantitative information on yield/time evolution by monitoring the progressive decrease of the maleimide peak at $293 \mathrm{~nm}$, associated with the corresponding loss of conjugation between the two carbonyl groups and the $\mathrm{C}=\mathrm{C}$ unsaturation separating them, which accompanies the formation of the DA adduct. Fig. 7 shows one of these sets of spectra, recorded for the DA polymerisation of VII + XII. The presence of an isosbestic point, common to all these experiments, clearly suggests that the polymerisation was not marred by side reactions.

The second-order rate constants obtained with all these polymerisations were in good agreement with those obtained previously from reactions of monofunctional model compounds (furfuryl acetate and $N$-methyl maleimide) in the same conditions. ${ }^{6}$ This observation is not surprising, since in both types of systems, the DA reaction involves the same diene and dienophile structures, i.e. a furan heterocycle substituted at $\mathrm{C} 2$ with a methylene group and a maleimide ring $N$-substituted by the

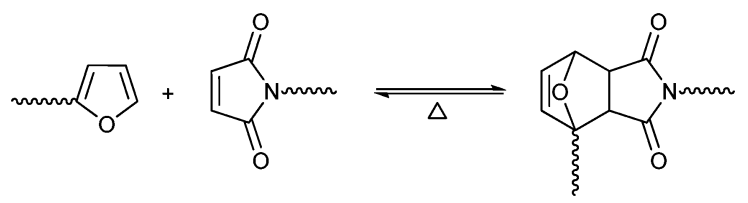

Scheme 8 The DA equilibrium between growing species bearing respectively furan and maleimide end groups. 


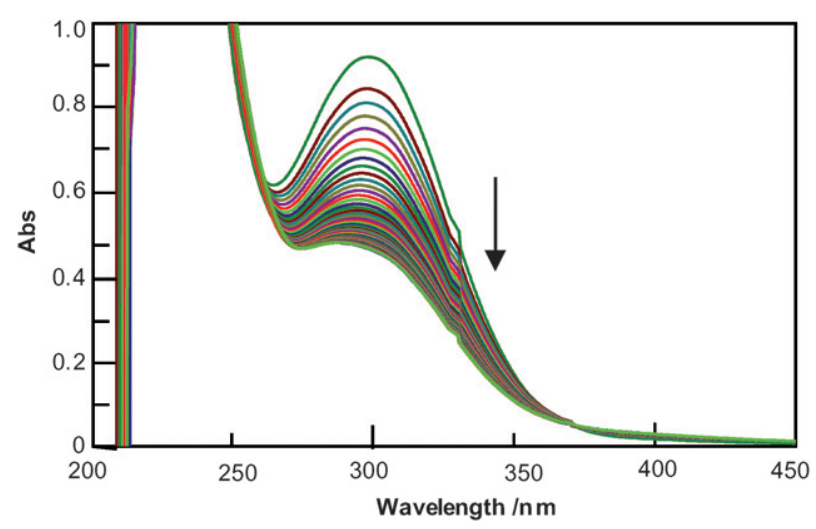

Fig. 7 Progressive decrease in the absorbance of the maleimide peak following the progress of the DA polymerisation of VII $(0.2 \mathrm{M})$ with XII $(0.2 \mathrm{M})$ in TCE at $65^{\circ} \mathrm{C}$. Spectra were taken every hour during $60 \mathrm{~h}$ with an optical path of $0.1 \mathrm{~mm}$.

same moiety. In other words, the reactivity of both DA partners did not depend detectably on the nature of their substituents beyond their first carbon atom.

The use of ${ }^{1} \mathrm{H}$ NMR spectroscopy to follow these polymerisations revealed all the details of the progressive increase in the signals associated with the adduct protons and the corresponding decrease of those attributed to the unreacted furan and maleimide cycles. Fig. 8 shows a typical spectrum related to the nearcompletion of the DA polycondensation of VII with XI.

The retro-DA depolymerisation of these materials was followed at $110^{\circ} \mathrm{C}$ by the same techniques. Fig. 9 shows a representative example of the UV spectroscopy observations.

For some systems, several polymerisation/depolymerisation cycles were applied reproducibly. In one instance, the polymer prepared from VII and XI was dissolved in toluene and submitted to the retro-DA reaction at reflux for $24 \mathrm{~h}$, after which an excess of 2,5-dimethylfuran (DMFu) was added to the solution while cooling the system to $65^{\circ} \mathrm{C}$ and leaving it for a further $24 \mathrm{~h}$. After the vacuum removal of toluene and the unreacted $\mathrm{DMFu}$, the residue was analysed by ${ }^{1} \mathrm{H}$ and ${ }^{13} \mathrm{C}$ NMR spectroscopy and shown to be an equimolar mixture of monomer VII and the bis-adduct of $\mathbf{X I}$ with DMFu. This result indicated that the polymer had indeed reverted to its monomers during the treatment in refluxing toluene $\left(110^{\circ} \mathrm{C}\right)$, but that the excess of

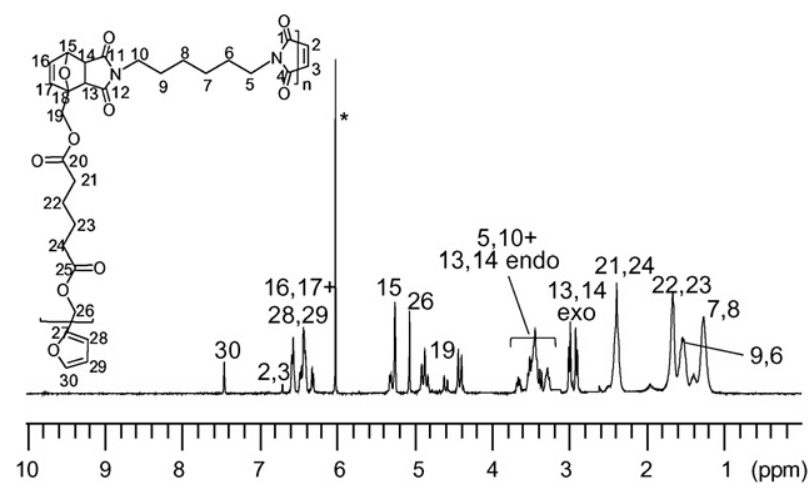

Fig. $8{ }^{1} \mathrm{H}-\mathrm{NMR}$ spectrum of the DA linear polymer VII + XI prepared in TCE- $\mathrm{d}_{2}(*)$ at $65^{\circ} \mathrm{C}$.

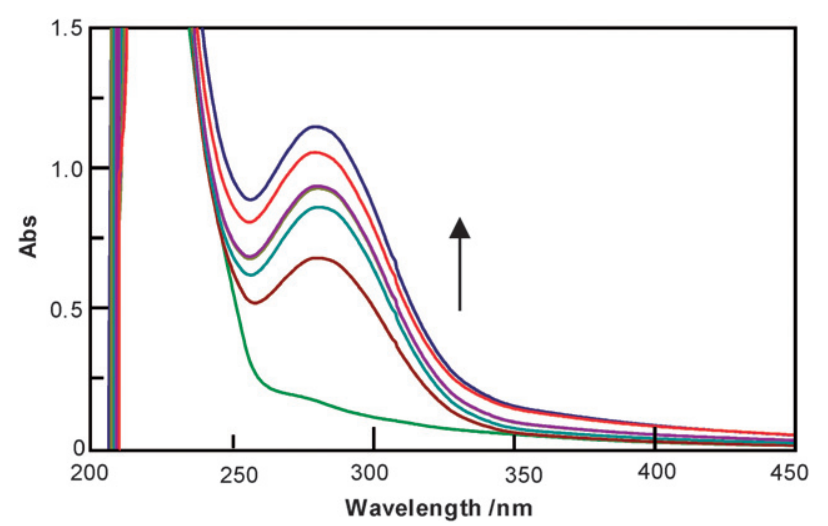

Fig. 9 Progressive increase in absorbance following the advancement of the retro-DA depolymerisation of polymer VII $+\mathbf{X I}$ in TCE at $110^{\circ} \mathrm{C}$. The regeneration of the monomers took about $24 \mathrm{~h}$.

DMFu had trapped the bismaleimide $\mathbf{X I}$ during the phase at $65^{\circ} \mathrm{C}$ by forming the corresponding bisadduct, thus inhibiting its DA repolymerisation with VII. A similar strategy had already been applied to avoid the return to a network structure after the decrosslinking of DA-based gels. ${ }^{12,13}$

The investigation of the non-linear DA polycondensations between each bisfuran and the trismaleimide XIII, or between each bismaleimide and each trisfuran, was carried out in the same experimental conditions and using the same spectroscopic tools. As expected, the use of complementary moiety stoichiometry produced a gel with every combination, whereas as the relative amount of trifunctional monomer was decreased, the reactions stopped short of crosslinking, i.e. gave soluble highly branched polymers. As a typical example of the behaviour of these systems, the reaction of bisfuran VII with the trismaleimide XIII was conducted at $65{ }^{\circ} \mathrm{C}$ in TCE or TCE- $\mathrm{d}_{2}$ with three [maleimide]/ [furan] molar ratios $r$, viz. 1.0, 0.75 and 0.50 , which, according to Flory-Stockmayer equation,

$$
\mathrm{Pc}=\frac{1}{\left[\mathrm{r}+\mathrm{r} \rho^{\prime}\left(\mathrm{m}^{\prime}-2\right)\right]^{1 / 2}}
$$

(in the present context, $\mathrm{m}=3$ for monomer XIII and $\rho=1$ because there is no other maleimide-type monomer in the system) are associated with critical conversions Pc for network formation of 50,71 and $100 \%$, respectively, if intermolecular cyclisations are neglected. Again, these reactions were followed by both UV (monomer concentrations of $\sim 0.1 \mathrm{M}$ ) and ${ }^{1} \mathrm{H}$ NMR spectroscopy (monomer concentrations of $\sim 1 \mathrm{M}$ ) and obviously here the increase in viscosity was much more pronounced than in the corresponding linear DA polymerisations discussed above. The reactions conducted with $\mathrm{r}=1.0$ with monomer concentrations close to $1 \mathrm{M}$, produced the most rapid thickening and gelled within a few days. Their counterparts with $r=0.75$ displayed similar features, albeit in a slower mode and the reduction of $\mathrm{r}$ to 0.50 only showed a slow progressive increase in viscosity without attaining a gel point, which is in tune with the fact that crosslinking would only be reached at $100 \%$ conversion in the absence of ring formation.

The evolution of the UV spectra with reaction time mimicked the features exemplified in Fig. 7, again accompanied by the regular occurrence of an isosbestic point. Fig. 10 shows the 


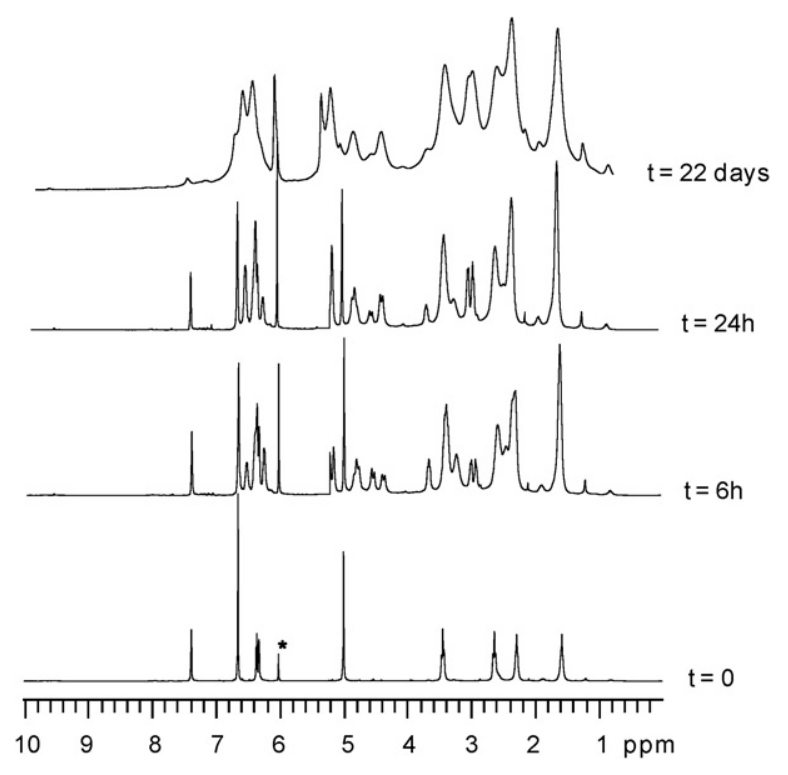

Fig. $10{ }^{1} \mathrm{H}$ NMR spectra of the evolution of the system VII + XIII, $r=1$ at $65^{\circ} \mathrm{C}\left(*\right.$ TCE- $\left.\mathrm{d}_{2}\right)$.

changes with time in the ${ }^{1} \mathrm{H}$ NMR spectra of the system VII + XIII under stoichiometric conditions $(\mathrm{r}=1.0)$. Apart from the specific decrease and growth related to the peaks associated with furan and maleimide protons and to those of the ensuing adducts, respectively, which were already examined and attributed in the study of the linear DA polymerisations (Fig. 8), the other relevant phenomenon was the considerable widening of all resonances reflecting the dramatic increase in molecular weight. Indeed, the last spectrum was taken well after the formation of the network, i.e. a mixture of crosslinked (gel) and branched (sol) macromolecules.

These gelled products were then heated at $110{ }^{\circ} \mathrm{C}$ and the spectra taken at regular intervals revealed the occurrence of the retro-DA depolymerisation (visually observed by the progressive dissolution of the gel fraction), giving a pattern that simulated the reverse sequence of that shown in Fig. 10. The repetition of this cycle produced the same quantitative phenomenologies. In one instance, the system depolymerised at $110^{\circ} \mathrm{C}$ was allowed to cool to $65^{\circ} \mathrm{C}$, after adding an excess of the DMFu DA trap, and left to react at that temperature for $24 \mathrm{~h}$ before vacuum removing the unreacted DMFu and part of the TCE- $\mathrm{d}_{2}$. The spectrum of the ensuing solution displayed the resonances of monomer VII together with those of the XIII-DMFu trisadduct, confirming the efficiency of the retro-DA depolymerisation in the regeneration of the starting monomers. The other non-linear polymerisations displayed the same general features.

An additional challenge in the application of the DA reaction to furan polymers is the synthesis and polycondensation of monomers bearing both reactive moieties in their structures, i.e. $\mathrm{AB}, \mathrm{ABn}$ and AnB molecules. The only study of one such system involving an $\mathrm{AB}$ monomer ${ }^{14}$ was rather ill conceived in that the furan and maleimide cycles were too close to each other and this seemed to affect their smooth DA multi-coupling. We have now synthesised several more viable AB structures, like monomer XVI, using amino acids as precursors. The reaction of their amino function with the furan DA adduct of maleic anhydride generated a protected maleimide moiety at one end of the molecule and the esterification of their carboxylic function with furfuryl alcohol introduced a furan heterocycle at the other end. ${ }^{15}$<smiles>O=C(CCN1C(=O)C2C3C=CC(O3)C2C1=O)OCc1ccco1</smiles>

These compounds are stable towards polymerisation until their adduct end-group is deprotected through the retro-DA reaction above about $100{ }^{\circ} \mathrm{C}$, which releases furan and generates the maleimide moiety. Hence the actual $\mathrm{AB}$ monomer is prepared in situ and its polymerisation can now be initiated at temperatures at which the equilibrium in Scheme 8 is predominantly shifted to the right. The interest here lies in the fact that $A B$ monomers provide the ideal stoichiometric situation for linear polycondensations. These polymerisations have been studied, together with the corresponding retro-DA monomer regeneration, and shown to occur without any side reaction over several cycles. ${ }^{15}$

\section{Conclusion}

The ongoing research discussed here on a couple of topics related to furan polymers will hopefully give a glimpse into the relevance of a much broader field in terms of building a viable alternative approach to macromolecular materials based on renewable resources. While the furan polyesters represent promising examples of how to replace counterparts derived from fossil sources, the exploitation of the Diels-Alder reaction opens original possibilities in terms of polymers with novel properties and applications. Both topics are being pursued in order to widen the range of materials, through, among other structures, novel furan polyesters and copolyesters and hyperbranched DA polymers.

\section{References}

1 M. N. Belgacem and A. Gandini, Eds., Monomers, Polymers and Composites from Renewable Resources, Elsevier, Amsterdam, 2008.

2 A. Gandini, Macromolecules, 2008, 41, 9491.

3 A. Gandini, Furan Polymers, in Encyclopedia of Polymer Science and Engineering, John Wiley \& Sons, New York, 1986, Vol. 7, p. 454; A. Gandini, ACS Symp. Ser., 1990, 433, 195; M. N. Belgacem and A. Gandini, Prog. Polym. Sci., 1997, 22, 1203; C. Moreau, A. Gandini and M. N. Belgacem, Top. Catal., 2004, 27, 9, A. Gandini and M. N. Belgacem, Furan Derivatives and Furan Chemistry at the Service of Macromolecular Materials, in ref. 1, chapter 6.

4 M. N. Belgacem and A. Gandini, ACS Symp. Ser., 2007, 954, 280.

5 P. Verdeguer, N. Merat and A. Gaset, J. Mol. Catal., 1993, 85, 327.

6 A. Gandini, D. Coelho and A. J. D. Silvestre, Eur. Polym. J., 2008, 44, 4029.

7 A. Gandini, Adv. Polym. Sci., 1977, 25, 47

8 J. A. Moore and J. E. Kelly, Macromolecules, 1978, 11, 568; J. A. Moore and J. E. Kelly, J. Polym. Sci., Polym. Chem. Ed., 1978, 16, 2407; J. A. Moore and J. E. Kelly, Polymer, 1979, 20, 627; J. A. Moore and J. E. Kelly, J. Polym. Sci., Polym. Chem. Ed., 1984, 22, 863; J. E. Kelly., Ph.D. Dissertation, Rensselaer Polytechnic Institute, N.Y., 1975. 
9 Y. Román-Leshkov, J. N. Chheda and J. A. Dumesic, Science, 2006, 312, 1933; F. S. Asgnari and H. Yoshida, Carbohydr. Res., 2006, 341, 2379; F. S. Asgnari and H. Yoshida, Ind. Eng. Chem. Res., 2006, 45, 2163; H. Zhao, J. E. Holladay, H. Brown and C. Zhang, Science, 2007, 316, 1597; J. N. Chheda, G. W. Huber and J. A. Dumesic, Angew. Chem., Int. Ed., 2007, 46, 7164; J. N. Chheda, Y. RománLeshkov and J. A. Dumesic, Green Chem., 2007, 9, 342; S. Hu, Z. Zhang, Y. Zhou, B. Han, H. Fan, W. Li, J. Song and Y. Xie, Green Chem., 2008, 10, 1280; G. Yong, Y. Zhang and J. Y. Ying, Angew. Chem., Int. Ed., 2008, 47, 9345; X. Qi, M. Watanabe, T. M. Aida and R. L. Smith Jr, Green Chem., 2008, 10, 799; X. Qi, M. Watanabe, T. M. Aida and R. L. Smith Jr, Ind. Eng. Chem.
Res., 2008, 47, 9234; Y. Román-Leshkov and J. A. Dumesic, Top. Catal., 2009, 52, 297.

10 A. Gandini, A. J. D. Silvestre, C. Pascoal Neto, A. F. Sousa and M. Gomes, J. Polym. Sci., Part A: Polym. Chem., 2009, 47, 295.

11 R. Storbeck and M. Ballauf, Polymer, 1993, 34, 5003.

12 C. Goussé, A. Gandini and P. Hodge, Macromolecules, 1998, 31, 314.

13 R. Gheneim, C. Pérez-Berumen and A. Gandini, Macromolecules, $2002,35,7246$.

14 C. Goussé and A. Gandini, Polym. Bull., 1998, 40, 389.

15 A. Gandini, D. Coelho and A. J. D. Silvestre, Macromolecules, submitted. 